\title{
Maternal Deaths in the City of Rio de Janeiro, Brazil, 2000-2003
}

\author{
Pauline Lorena Kale and Antonio Jose Leal Costa \\ Medical School and Institute of Public Health Studies, Federal University of Rio de Janeiro (IESC/UFRJ), \\ Praça Jorge Machado Moreira, 100 Cidade Universitária Ilha do Fundão, Rio de Janeiro, RJ, Brazil-CEP 21944-970
}

\begin{abstract}
The study describes the characteristics of maternal deaths in the city of Rio de Janeiro, Brazil, during 20002003. After investigation by public-health services, 217 maternal deaths were identified among predominantly non-white (48.9\%), single (57.1\%) women aged $29.6 \pm 7.3$ years on average. Direct obstetric causes corresponded to $77.4 \%$ of the maternal deaths, mainly due to hypertensive disorders. HIV-related diseases accounted for $4 \%$ of the maternal deaths. Almost three-fourths of the mothers who died were aged 20-39 years, although the highest risk of maternal death corresponded to the age-group of 40-49 years (248.9 per 100,000 livebirths). The socioeconomic and demographic profiles of maternal deaths in the city of Rio de Janeiro reflected a vulnerable social situation. Appropriate interventions aimed at reducing maternal mortality need to encompass all women of childbearing age, irrespective of the magnitude of the risk of maternal death.
\end{abstract}

Key words: Causes of death; HIV; Hypertensive disorders; Maternal health; Maternal mortality; Vital statistics; Women's health; Brazil

\section{INTRODUCTION}

In the United Nations' 2000 declaration of the Millennium Development Goals, improvement of maternal health was regarded as an essential prerequisite for human development and for poverty reduction (1). Although pregnancy is a normal life-course event that most women aspire to at some point in their lives, about eight million women develop pregnancy-related complications every year, and of them, over half a million die (2). Even in the context of limited resources, most of these deaths could be avoided if preventive measures were taken and adequate care was available (1). However, the right kind of information on which maternal mortality-prevention strategies are based is often missing (2).

In Brazil, deaths are registered in the national mortality information system (SIM) of the Ministry of

Correspondence and reprint requests should be addressed to:

Dr. Pauline L. Kale

Institute of Public Health Studies

Federal University of Rio de Janeiro (IESC/UFRJ)

Praça Jorge Machado Moreira

100, Cidade Universitária

Ilha do Fundão, Rio de Janeiro, RJ

Brazil-CEP 21944-970

Email: pkale@iesc.ufri.br

Fax: 55212598.9331
Health. Its coverage has been systematically increasing since its inception in 1976, reaching $82 \%$ nationwide by 1999 , albeit with marked regional variation. Of all the registered deaths, maternal deaths are particularly problematic, mainly due to inadequate assignment of causes of death in death certificates.

As a strategy to improve the registration of maternal deaths, starting in 1994, the Ministry of Health of Brazil has encouraged the creation of the Perinatal and Maternal Mortality Investigation Committees at both State and County Health Departments (3). Moreover, information on pregnancy, abortion, parturition, or puerperium in all women of reproductive age at death has been added to both national death certificate form and SIM. In addition, maternal death reporting to the public-health surveillance system within 24 hours after demise has been mandated (4).

In 2002, a nationwide study of maternal mortality was carried out in most Brazilian state capitals (5). Based on household interviews and investigation of medical and hospital records and autopsies (the Reproductive Age Mortality Study methodologyRAMOS), the maternal mortality ratios (MMRs) were estimated, which were lower than the values reported by the World Health Organization (WHO), 
United Nations Children's Fund, and United Nations Population Fund. The estimated MMR adjustment factor for official data in Brazil was equal to 1.4 -representing a $40 \%$ under-registration of maternal deaths - based upon which the adjusted MMR was 54.3 maternal deaths per 100,000 livebirths. The authors highlighted the heterogeneous validity of data on maternal mortality across Brazilian regions: quality of data was poorer in the north and northeast regions compared to the south and southeast regions where validity was higher. Direct obstetric causes accounted for $67.1 \%$ of all maternal deaths, suggesting that both prenatal and childbirth care must be improved.

As the epidemiological assessment of maternal mortality is important in revising old and developing new public-health strategies of prevention, we analyzed maternal deaths according to demographic, educational and obstetric characteristics in the city of Rio de Janeiro from 2000 to 2003.

\section{MATERIALS AND METHODS}

The study was conducted in the city of Rio de Janeiro, the capital of Rio de Janeiro state, situated in the southeast region of Brazil. In 2000, the city had a population of $5,857,904$ inhabitants; the average number of livebirths per woman in reproductive ages (15-49 years) was 1.8 (6), and 99\% occurred in hospital settings (7).

Data on maternal mortality were obtained from the SIM and from records provided by the Perinatal and Maternal Mortality Investigation Committee (PMMIC) of the city of Rio de Janeiro. Livebirth data were collected from the national livebirth information system (SINASC). Both information systems-SIM and SINASC_-have high coverage within the state of Rio de Janeiro (8).

The WHO defines maternal death as "the death of a woman while pregnant or within 42 days of termination of pregnancy, irrespective of the duration and the site of the pregnancy, from any cause related to or aggravated by the pregnancy or its management but not from accidental or incidental causes." Separate definitions were used for two categories of maternal deaths based on cause of death, which were termed 'direct obstetric deaths' and 'indirect obstetric deaths'. Direct obstetric deaths included deaths "resulting from obstetric complications of the pregnant state" while indirect obstetric deaths were defined as "deaths resulting from pre-existing disease or disease that developed during pregnancy, not due to direct obstetric causes, but exacerbated by the physiologic effects of pregnancy" (9).

Maternal deaths of women living in the city of Rio de Janeiro during 2000-2003 were investigated by the public-health surveillance services and further confirmed by the city's PMMIC. Independent variables considered in analyses, as registered in the death certificates, were: age, race/colour (reported by the doctor who submitted the death certificates), marital status, years of schooling, place where death occurred (inside or outside hospital or clinic), reporting to the public-health surveillance system and pregnancy status (whether death occurred during an abortion, pregnancy, or parturition-yes, no, or ignored, or puerperium-yes (within 42 days after delivery or after 42 days up to one year after delivery), no or ignored), and the cause of death, according to the $10^{\text {th }}$ revision of the International Classification of Diseases (ICD 10). Completeness of mortality data was evaluated through the proportion of missing information for each variable considered in the analyses.

The MMRs were estimated as the number of maternal deaths per 100,000 livebirths. Maternal deaths comprised all deaths due to obstetric causes (ICD 10, Chapter XV: Direct obstetric causes, Codes O00 to O92; unspecified obstetric causes, Code O95; indirect obstetric causes, Codes O98 to O99, except Codes O96 and O97-_late maternal deaths occurring more than 42 days but less than one year after delivery and death from sequelae of direct obstetric causes" respectively) and other selected causes outside Chapter XV as follows: 'Human immunodeficiency virus (HIV) disease', Codes B20 to B24, Chapter I: 'Neoplasms of uncertain or unknown behaviour of placenta', Code D39.2; Chapter II: 'Hypopituitarism', Code E23.0; Chapter IV: 'Mental and behavioural disorders associated with the puerperium, not elsewhere classified', Code F53; Chapter V: 'Osteomalazie', Code M83.0; and Chapter XII. The $95 \%$ confidence intervals (CIs) of the MMRs were also estimated (10).

\section{RESULTS}

In total, 217 maternal deaths occurring during 2000-2003 in the city of Rio de Janeiro were identified, of which 208 (95.9\%) were classified as due to obstetric causes (Chapter XV, except Codes O96 and 097). The remaining nine deaths, due to HIV disease (Codes B20 to B24, Chapter I), were classified, after investigation, as indirect obstetric causes. Fourteen additional deaths were also identified, of which nine had their causes coded as O96 (late ma- 
ternal deaths) and five as O97 (death from sequelae of direct obstetric causes). Since all these additional 14 maternal deaths occurred 42 or more days after delivery, they were excluded from the present analyses.

Of the 217 maternal deaths, 58.1\% were not reported to the public surveillance system. Most (94.1\%) deaths occurred in a hospital setting. Less than $1.0 \%$ of the maternal deaths occurred at health clinics, and in 5\%, information on place where death occurred was missing.

The demographic, educational and obstetric characteristics of the maternal deaths are presented in Table 1.

\begin{tabular}{|c|c|c|}
\hline \multicolumn{3}{|c|}{$\begin{array}{l}\text { Table 1. Demographic, educational and obstetric } \\
\text { characteristics of maternal deaths, City } \\
\text { of Rio de Janeiro, Brazil, 2000-2003 }\end{array}$} \\
\hline Characteristics & No. & $\%$ \\
\hline \multicolumn{3}{|l|}{ Age (years) } \\
\hline $10-19$ & 32 & 14.7 \\
\hline $20-29$ & 75 & 34.6 \\
\hline $30-39$ & 85 & 39.2 \\
\hline $40-49$ & 25 & 11.5 \\
\hline Unknown & 0 & 0.0 \\
\hline \multicolumn{3}{|l|}{ Race/colour } \\
\hline White & 92 & 42.4 \\
\hline Black & 34 & 15.7 \\
\hline Brown or mixed race & 72 & 33.2 \\
\hline Unknown & 19 & 8.8 \\
\hline \multicolumn{3}{|l|}{ Marital status } \\
\hline Single & 124 & 57.1 \\
\hline Married (with civil registration) & 64 & 29.5 \\
\hline Married (without civil registration) & 4 & 1.8 \\
\hline Widow & 1 & 0.5 \\
\hline Separated & 6 & 2.8 \\
\hline Unknown & 18 & 8.3 \\
\hline \multicolumn{3}{|l|}{ Schooling (years) } \\
\hline 0 & 4 & 1.8 \\
\hline $1-3$ & 36 & 16.6 \\
\hline $4-7$ & 64 & 29.5 \\
\hline $8-11$ & 49 & 22.6 \\
\hline 12 or more & 15 & 6.9 \\
\hline Unknown & 49 & 22.6 \\
\hline \multicolumn{3}{|l|}{ Pregnancy status } \\
\hline Pregnancy/parturition or abortion & 42 & 19.4 \\
\hline $\begin{array}{l}\text { Puerperium up to } 42 \text { days after } \\
\text { delivery }\end{array}$ & 80 & 36.8 \\
\hline Inconsistent information & 37 & 17.1 \\
\hline Unknown & 58 & 26.7 \\
\hline
\end{tabular}

Age varied from 14 to 44 years (median: 30.0 years; mean \pm standard deviation (SD): $29.6 \pm 7.3$ years). Approximately one (14.7\%) in seven women was adolescent (aged 10-19 years), with one death occurring under the age of 15 years. In the other extreme of the age distribution, $11.5 \%$ of the women died at ages above 39 years. Almost three-quarters of the maternal deaths occurred between age 20 years and 39 years. All death certificates had data on age at death.

The deceased women were predominantly nonwhite $(48.9 \%)$, single (57.1\%), and had $4-11$ years of schooling $(52.1 \%)$. However, data on years of schooling were missing in $22.6 \%$ of the death certificates.

Among all variables considered in the analysis, the variable for which most data were missing (43.8\%) was pregnancy status at the time of death. In $26.7 \%$ of the death certificates, doctors who provided care reported that they ignored whether death had occurred during an abortion, pregnancy, delivery, or puerperium; in $17.1 \%$, data on pregnancy status were either conflicting (death was reported to have happened during abortion, pregnancy, or delivery and during puerperium in $9.2 \%$ ), or insufficient (data were missing on death prior to or during puerperium in $7.9 \%)$. Considering only death certificates with adequate information (56.2\%), for each maternal death that occurred during pregnancy or at parturition, about two women died during puerperium.

More than three $(77.4 \%)$ in four maternal deaths of women living in the city of Rio de Janeiro from 2000 to 2003 were due to direct obstetric causes (Table 2). Hypertensive disorders (Codes O10 to O16) were the most common cause of death, accounting for $26.3 \%$ of all maternal deaths and for $33.9 \%$ of all direct obstetric causes. Pre-eclampsia (Code O14) and eclampsia (Code O15) accounted for, respectively, 12 (7.1\%) and 19 (11.3\%) deaths due to hypertensive disorders. Abortion (Codes O00 to O08) was the third main cause of death, accounting for almost one (14.3\%) in seven of the total deaths-and the third cause among deaths due to direct obstetric causes (18.5\%). Indirect obstetric causes of death contributed to $17.5 \%$ of the total maternal deaths. "Other maternal diseases classifiable elsewhere but complicating pregnancy, childbirth and the puerperium" (Code O99) were the most frequent indirect obstetric causes of death $(73.7 \%)$ mainly due to diseases of the circulatory system (Code O99.4). The only cause of maternal death coded outside Chapter XV of ICD-10 (pregnancy, childbirth, and the puerperium) was 'Hu- 


\begin{tabular}{|c|c|c|c|}
\hline Cause of death & No. & $\begin{array}{l}\% \text { within } \\
\text { group }\end{array}$ & $\begin{array}{c}\% \\
\text { of total }\end{array}$ \\
\hline Direct obstetric causes (Codes O00-O92) & 168 & 100.0 & 77.4 \\
\hline Pregnancy with abortive outcome (O00-O08) & 31 & 18.5 & 14.3 \\
\hline Oedema. Proteinuria, and hypertensive disorders (O10-O16) & 57 & 33.9 & 26.3 \\
\hline Pre-eclampsia (O14) & 12 & 7.1 & 5.5 \\
\hline Eclampsia (O15) & 19 & 11.3 & 8.8 \\
\hline Gestational hypertension (O13) & 12 & 7.1 & 5.5 \\
\hline Unspecified maternal hypertension (O16) & 9 & 5.4 & 4.1 \\
\hline Others causes & 5 & 3.0 & 2.3 \\
\hline Other maternal disorders predominantly relating to pregnancy (O20-O29) & 3 & 1.8 & 1.4 \\
\hline $\begin{array}{l}\text { Maternal care relating to the foetus/amniotic cavity/possible delivery } \\
\text { problems (O30-O48) }\end{array}$ & 24 & 14.3 & 11.1 \\
\hline Premature separation of placenta $(\mathrm{O} 45)$ & 13 & 7.7 & 6.0 \\
\hline Other causes & 11 & 6.5 & 5.1 \\
\hline Complications of labour and delivery (O60-O75) & 20 & 11.9 & 9.2 \\
\hline Other uterine inertia (O622.2) & 12 & 7.1 & 5.5 \\
\hline Other causes & 8 & 4.8 & 3.7 \\
\hline Complications predominantly relating to puerperium (O85-O92) & 33 & 19.6 & 15.2 \\
\hline Puerperal sepsis (O85) & 13 & 7.7 & 6.0 \\
\hline Obstetric embolism (O88) & 12 & 7.1 & 5.5 \\
\hline Other causes & 8 & 4.8 & 3.7 \\
\hline Other obstetric conditions, not elsewhere classified (O95) & 11 & 100.0 & 5.1 \\
\hline Indirect obstetric causes (O98 e O99 + B20 to $\left.\mathrm{B} 24^{\star}\right)$ & 38 & 100.0 & 17.5 \\
\hline Maternal infectious and parasitic diseases (O98) & 1 & 2.6 & 0.5 \\
\hline Other maternal diseases (O99) & 28 & 73.7 & 12.9 \\
\hline Diseases of the circulatory system (O99.4) & 11 & 28.9 & 5.1 \\
\hline Diseases of the respiratory system (O99.5) & 5 & 13.2 & 2.3 \\
\hline $\begin{array}{l}\text { Other specified diseases/conditions complicating pregnancy/childbirth/ } \\
\text { puerperium (O99.8) }\end{array}$ & 8 & 21.1 & 3.7 \\
\hline Other causes & 4 & 10.5 & 1.8 \\
\hline Human immunodeficiency virus (HIV) disease (B20-B24) $\dagger$ & 9 & 23.7 & 4.1 \\
\hline Total & 217 & - & 100.0 \\
\hline
\end{tabular}

man immunodeficiency virus (HIV) disease' (Codes B20 to B24), accounting for about $4 \%$ of the total maternal deaths and $23.7 \%$ of all deaths due to indirect obstetric causes. In only one (5.1\%) in 20 maternal deaths, the obstetric cause was not specified (Code O95).

The distributions of demographic and educational characteristics of women who died due to direct obstetric causes were similar to those observed for all maternal deaths shown in Table 1. Such pattern differed from that observed for maternal deaths due to unspecified or indirect obstetric causes, except for marital status (mainly single women across all categories of cause of maternal death). Women who died due to "other obstetric conditions, not elsewhere classified" (Code O95) were predominantly brown/coloured or of mixed races (45.5\%) and had a lower educational level [36.4\% had 1-3 year(s) of schooling]. Those who died from indirect causes were younger (about 55\% were aged 20-29 years) and had a higher educational level (about 29\% had 8-11 years of schooling) (data not shown). 
Both maternal deaths and livebirths registered in the city of Rio de Janeiro each year decreased from 2000 to 2003. During these four years, there was a slightly declining trend in the MMR, although it was irregular and not statistically significant (data not shown). Overall, approximately 60 maternal deaths occurred for each 100,000 livebirths (MMR=59.5; 95\% CI 51.6-68.4 per 100,000 livebirths) in the city of Rio de Janeiro during 20002003.

The MMR varied according to maternal age: its lowest value-39.7 per 100,000 livebirths (95\% CI 30.6-51.6) - corresponded to the age-group of 2029 years (Fig.), thus taken as a reference category for comparison purposes. Among the adolescents ( $n=68,392$ livebirths), the MMR was $18 \%$ higher than the estimate for the age-group of 20-29 years, i.e. 46.8 per 100,000 livebirths (95\% CI 36.0-60.8). The risk of dying due to maternal causes, as estimated by the MMR, increased in older ages, reaching 86.7 (95\% CI 64.3-114.4) and 283.3 (95\% CI 206.5-379.6) per 100,000 livebirths, respectively, for women aged 30-39 and 40-49 years. Compared to the age-group of 20-29 years, the MMR found for the age-groups of 30-39 years and 40-49 years was 2.2 and 7.1 times higher respectively.

The contribution of the number of deaths due to indirect obstetric causes was superior in the agegroups of 20-29 years and 30-39 years when compared with older ages, mainly because of HIV disease (Codes B20 to B24) and other maternal diseases classifiable elsewhere but complicating pregnancy, childbirth, and the puerperium (Code O99) (Fig.).

\section{DISCUSSION}

In total, 217 maternal deaths occurring in the city of Rio de Janeiro during 2000-2003 were confirmed by the city's PMMIC. Such deaths were derived from a larger subset eligible for investigation by the public-health surveillance services, which comprises only deaths whose cause, as registered in the death certificate was primarily due to an obstetric cause or classified as a presumable cause of maternal death, according to the routine surveillance procedures. Therefore, there is a potential for under-reporting of maternal deaths, since not all deaths of women of childbearing age were investigated. Although possible, additional under-reporting due to lack of registration of maternal deaths was unlikely, since, as previously highlighted, the SIM has a high coverage within the state of Rio de Janeiro (8). It should, however, be emphasized that, if maternal deaths were under-reported, the corresponding risks of dying from maternal causes were also underestimated. Even if underestimated, the

Fig. Number of maternal deaths by categories of obstetric cause of death (ICD-10) and maternal mortality ratio per 100,000 livebirths, according to maternal age at death, City of Rio de Janeiro, Brazil, 2000-2003

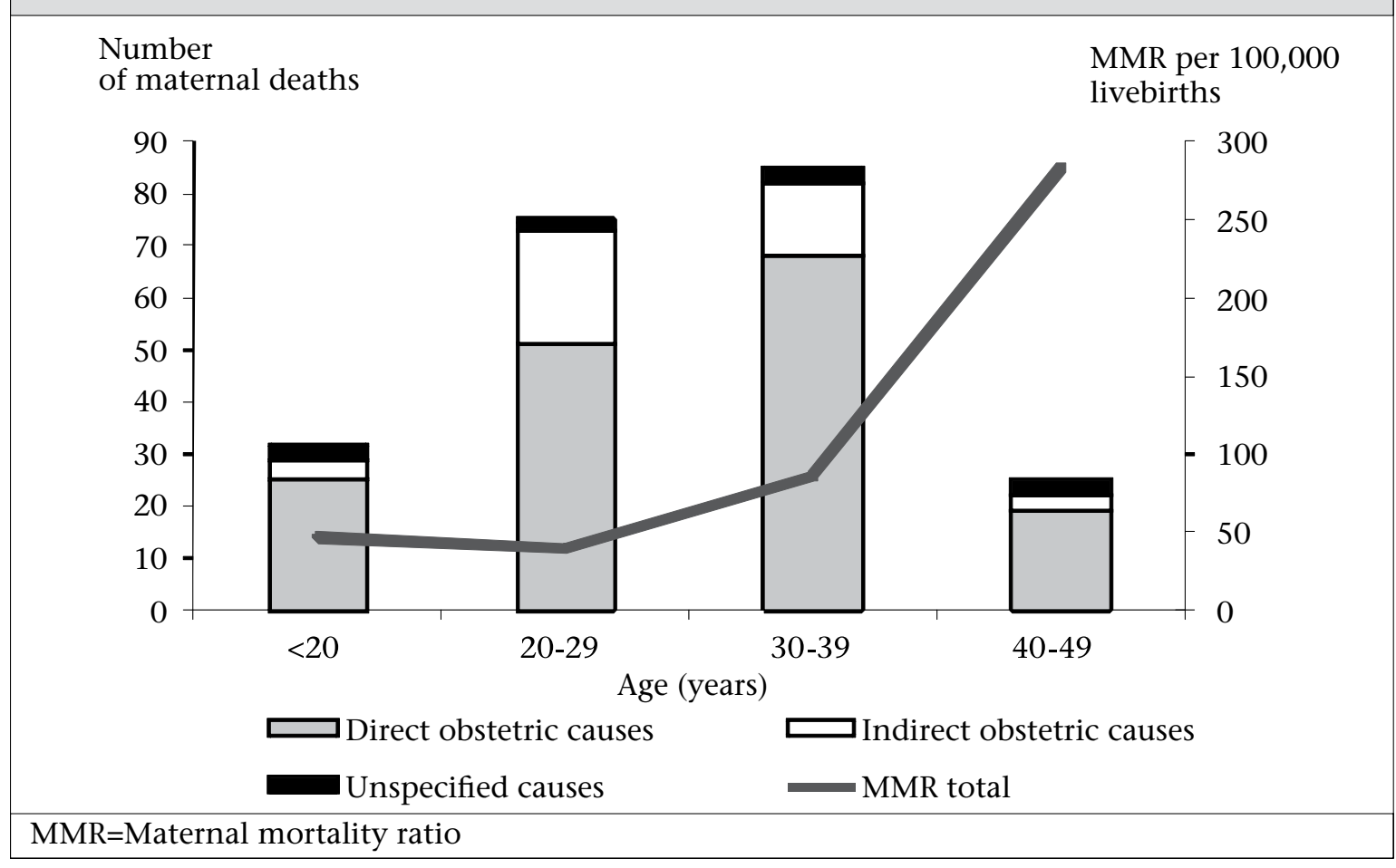


overall MMR found in our study—59.5 per 100,000 livebirths-still exceeded by about 3-6 times the range of values for the MMR regarded as acceptable by the WHO-between 10 and 20 per 100,000 livebirths (11), revealing, thus, a high risk of dying due to maternal causes in the city of Rio de Janeiro during 2000-2003.

Following the recommendation of the WHO for international comparisons (9), both late maternal deaths (Code O96, Chapter XV) and deaths from sequelae of direct obstetric causes (Code O97, Chapter XV) were not included in the MMR estimates. Their inclusion would have obviously increased maternal mortality beyond our estimates, as they totalled 231 deaths during 2000-2003. Of these, 217 were confirmed maternal deaths (208 classified as due to obstetric causes-Chapter XV, except Codes O96 and O97 and nine deaths, due to HIV disease Codes B20 to B24, Chapter I) plus nine late maternal deaths and five deaths from sequelae of direct obstetric causes. The proportion of late maternal deaths (4.0\%) is considered low when compared with those of developed countries (5-20\% of all maternal deaths). Such finding is somewhat expected since access to treatments and technology to prolong life may still be restricted in developing countries (2).

The socioeconomic profile of the study women who died from maternal causes reflects a vulnerable social situation. In the city of Rio de Janeiro, from 2000 to $2003,60 \%$ of deaths of women for whom race/colour was known were non-white (black or brown/mixed-raced), which exceeds by about $50 \%$ the proportion of non-white women in the female population aged 10-49 years living in the city in 2000 (6). Notwithstanding the difficulty to properly assess race/colour in Brazil, such a high proportion of non-white maternal deaths is a very likely reflection of social inequality (12). Schooling is another important marker of vulnerability (13). Considering only deaths for which data on educational level were available in the death certificate (168), only about $62 \%$ had completed seven years of schooling - a proportion that was much higher than that in women aged 15 years or more living in the city of Rio de Janeiro in 2000 (39\%), further underscoring the strong association of socioeconomic status with maternal mortality (6). The finding that as many as $57 \%$ of the deceased women were single at the moment of death also emphasizes the importance of social vulnerability in the causation of maternal mortality (13). Global policies are important to promote equity in health and, particularly, to reduce maternal mortality.
Factors relating to the quality and organization of healthcare services strongly influence the survival of women with pregnancy-related complications $(13,14)$. A survey of 47 maternity hospitals in the city of Rio de Janeiro during 1999-2001 showed that $71.8 \%$ of postpartum women began their prenatal care during the first three months of pregnancy, with $61.5 \%$ reporting seven or more prenatal visits. The overall maternal health conditions during pregnancy and delivery and the quality of healthcare at delivery were better in public than in private hospitals (15). Although the coverage of public maternity services is high, the public-health system (SUS) fails to assure a place for delivery for all women on a timely basis (16). In addition, there may be problems with the quality of healthcare during the prenatal phase and delivery, which can result in health complications to both mothers and babies $(1,14)$.

In our study, women who died from maternal causes were predominately aged $30-39$ years $(39.2 \%)$, similar to the results reported by Horon et al. in Maryland, USA (46.5\%) from 1993 to 2000 (17) and unlike the studies conducted in Ankara, Turkey, during 1982-2001 (14) and in Bangladesh during 1996-1997 (18), in which maternal deaths occurred mainly at the age of $20-29$ years $(48.2 \%$ and $33.6 \%$ respectively). On the other hand, in the city of Rio de Janeiro, the highest risk of maternal death was seen at the age of 40-49 years (MMR=248.9 per 100,000 livebirths). Conversely, more than onethird of deaths occurred at the age of 20-29 years, although at these ages the risk of maternal death was the lowest. Such findings illustrate one of the most fundamental axioms in preventive medicine: a large number of people exposed to a small risk may generate many more cases than a small number exposed to a high risk (19). Thus, appropriate interventions aimed at reducing maternal mortality must not be based solely on a high-risk strategy but need to encompass all women at childbearing ages regardless of the magnitude of the age-related risk of maternal death.

The distribution of causes of maternal deaths in the city of Rio de Janeiro was closer to the patterns observed in Ankara (14) and Bangladesh (18) than to what was found in a study done in Maryland, USA (17). Direct obstetric causes of death played a major role in our study mainly due to eclampsia/ pre-eclampsia (hypertensive disorders). Abortion was also an important cause of death in the city of Rio de Janeiro, accounting for $19.0 \%$ of all maternal deaths. In the province of Santa Fe, Argentina, hypertensive disorders were the main cause 
of maternal deaths in the periods before, and for a few years after the inclusion of the pregnancy status check-box in death certificate in 1994; however, in 2001, abortion became the most frequent cause (20). In St. Petersburg, Russia, abortion was the main cause of maternal deaths (35.0\%) from 1992 to 2003 (21). In 2006, a systematic review was undertaken to determine the distribution of causes of maternal deaths worldwide: in Africa and Asia, haemorrhage was the leading cause of death, and, in Latin America and the Caribean, hypertensive disorders ranked first (22). In locations where the MMRs were low, such as Bavaria, the USA, Sweden, and the United Kingdom, the leading cause of maternal deaths was thromboembolism which is difficult to prevent (21). HIV infection caused $4 \%$ of the total maternal deaths in the city of Rio de Janeiro. Thus, providing support for helping women who need to use antiretroviral drugs before and during pregnancy is also an important strategy for prevention of maternal and also childhood deaths (1).

More efforts are needed to increase the effectiveness of the strategies aimed at improving maternal death report in Brazil. First, in the present study, maternal deaths were poorly reported by the surveillance system (coverage of about $42 \%$ ). Also, the inclusion in the death certificate of information about abortion, pregnancy, delivery, and puerperium at or during the 12 months that preceded deaths of women of reproductive age, if correctly filled, would also help improve the ascertainment of maternal deaths. Both physicians and medical students should be better trained on how to complete a death certificate adequately. In our study, information about the maternal condition was properly recorded in $56 \%$ of maternal death certificates. The addition of the maternal condition at the time of death in the death certificate was followed by a decrease of under-reporting of maternal deaths in the province of Santa Fe, Argentina (18). Moreover, completeness of reporting of deaths relating to pregnancy, delivery, and puerperium could also be improved by linking death records of women of reproductive ages to birth and foetal death records (16). Such strategy has already been used at the State Health Department of Rio de Janeiro, although not in a systematic way. Finally, more sensitive criteria to select the death certificate for field investigation should be adopted by the PMMIC of the city of Rio de Janeiro and should encompass the investigation of all pregnancy-related deaths.

In conclusion, more efforts are needed to achieve the 2000 Millennium Development Goals of a 75\% reduction of maternal mortality by 2015 in the city of Rio de Janeiro (1). At present, efforts are being developed by the SIM and CCMMP towards improving the quality of data on maternal deaths in Brazil, an important step to provide programme-oriented strategies aimed at reducing maternal mortality. Both health sector-specific and intersectoral intervention policies are important to promote the survival and well-being of mothers and their babies.

\section{ACKNOWLEDGEMENTS}

This study was supported by the Research Support Foundation, Rio de Janeiro state (FAPERJ).

The authors thank Janaina V. Costa (public-health student of IESC/UFRJ) and Fernando D.S. Motta (undergraduate student at the Medical School/ UFRJ) for their cooperation during data collection and processing and Mariza Miranda Theme-Filha (Health Department of the City of Rio de Janeiro) for providing the mortality database. An earlier version this paper was presented at the 2006 Population Studies Brazilian Association (ABEP) Meeting held in, Caxambu, Minas Gerais, Brazil, on 18-22 September 2006.

\section{REFERENCES}

1. United Nations. Department of Public Information. We the people. The role of United Nations in the 21st century. New York, NY: Department of Public Information, United Nations, 2000:1-80.

2. World Health Organization. Beyond the numbers. Reviewing maternal deaths and complications to make pregnancy safer. Geneva: World Health Organization, 2004:1-150.

3. Brasil. Ministério da Saúde. Portaria $n^{\circ} 773$, de 07 de abril de 1994. Brasília, DF: Diário Oficial da União, 1994.

4. Brasil. Ministério da Saúde. Resolução n 256, de um de outubro de 1997. Brasília, DF: Diário Oficial daUnião, 1997. (http://bvsms.saude.gov.br/bvs/ saudelegis/cns/1997/res0256_01_10_1997.html, accessed on 05 January 2008).

5. Laurenti R, Mello Jorge MHP, Gotlieb SLD. Maternal mortality in Brazilian State Capitals: some characteristics and estimates for an adjustment factor. Rev Bras Epidemiol 2004;7:449-60.

6. Fundação Instituto Brasileiro de Geografia e Estatística. Censo demográfico 2001. Fundação Instituto Brasileiro de Geografia e Estatística. (http://www. sidra.ibge.gov.br/cd/cd2000ru.asp?o=4\&i=P.htm, accessed on 12 April 2008).

7. Brasil. Ministério da Saúde. Informações de saúde. Brasília, DF: Ministério da Saúde. (http://w3.datasus. 
gov.br/datasus/datasus.php, accessed on 7 January 2008).

8. Rede Interagencial de Informações para a Saúde. Comitê temático interdisciplinar (CTI): informações sobre indicadores desigualdades em Saúde-IDS. Brasília, DF: Rede Interagencial de Informações para a Saúde, 2002. 2 p.

9. World Health Organization. International statistical classification of diseases and health related problems-ICD-10. V. 1. 2nd ed. Geneva: World Health Organization, 2004:1-169.

10. Haenszel W, Loveland DB, Sirken MG. Lung cancer mortality as related to residence and smoking histories I: white males. Nat Cancer Inst 1962;28:9471001.

11. World Health Organization. Revised 1990 estimates of maternal mortality: a new approach by WHO and UNICEF. Geneva: World Health Organization, 1996:116. (WHO/FRH/MSM/96.11; UNICEF/PLN/96.1).

12. Martins AL. Maternal mortality among black women in Brazil. Cad Saúde Pública 2006;22:2473-9.

13. Goodrum LA. Maternal mortality: strategies in prevention and care. Hosp Physician 2001;(Jan):44-51.

14. Akar ME, Eyi EGY, Yilmaz ES, Yuksel B, Yilmaz Z. Maternal deaths and their causes in Ankara,Turkey, 1982-2001. J Health Popul Nutr 2004;22:420-8.

15. Leal MC, Gama SGN, Campos MR Cavalini LT, Garbayo LS, Brasil CLP et al. Factors associated with precarious prenatal care in a sample of post-partum adolescent mothers in maternity hospitals in Rio de Janeiro, Brazil, 1999-2000. Cad Saúde Pública 2004;20(Suppl1):S20-33.

16. Valongueiro S, Ludermir AB, Gominho LAF. Evaluation of procedures for identifying maternal deaths. Cad Saúde Pública 2003;19(Supp 12):S293-301.

17. Horon, IL. Underreporting of maternal deaths on death certificates and the magnitude of the problem of maternal mortality. Am J Public Healt 2005;95;47882.

18. Yusuf HR, Akhter HH, Chowdhury ME, Rochat RW. Causes of death among women aged 10-50 years in Bangladesh, 1996-1997. J Health Popul Nutr 2007;25:302-11.

19. Rose G. The relation of risk to exposure. The strategy of preventive medicine. New York, NY: Oxford University Press, 1992:15-28.

20. Elizalde EG. Análisis de la ocurrencia de la mortalidad materna en la provincia de Santa Fe-Argentina, a propósito de una intervención. Rev Bras Epidemiol 2004;7:435-47.

21. Gurina NA, Vangen S, Forsen L, Sundby J. Maternal mortality in St. Petersburg, Russian Federation. Bull World Health Organ 2006;84:283-9.

22. Khan KS, Wojdyla D, Say L, Gülmezoglu AM, Van Look PFA. WHO analysis of causes of maternal death: a systematic review. Lancet 2006;367:1066-74. 